\title{
Session 4aAO
}

\section{Acoustical Oceanography, Signal Processing in Acoustics, and ECUA: Adjoint Modeling for Geoacoustic Inversion}

\author{
Paul Hursky, Cochair \\ HLS Research, Inc., 3366 N. Torrey Pines Ct., Ste. 310, La Jolla, CA 92037, USA \\ Jean-Pierre Hermand, Cochair \\ Université libre de Bruxelles (U.L.B.) - Environmental hydroacoustics lab, av. Franklin D. Roosevelt 50, CP 194/5, Bruxelles, \\ 1050, Belgium
}

Invited Papers

11:00

\begin{abstract}
4aAO1. Validation of adjoint-generated environmental gradients for the acoustic monitoring of a shallow water area. Matthias Meyer (Royal Netherlands Naval College (NLDA) - REA group, PO Box 10000, 1780 Den Helder, Netherlands, mmeyer@ulb.ac.be), Jean-Pierre Hermand (Université libre de Bruxelles (U.L.B.) - Environmental hydroacoustics lab, av. Franklin D. Roosevelt 50, CP 194/5, 1050 Bruxelles, Belgium, jhermand@ulb.ac.be), Mohamed Berrada (Laboratoire d'Océanographie et du Climat - Expérimentation et Approches Numériques, Université Pierre et Marie Curie, Tour 45-55 - 5ème étage - 4, place Jussieu, 75005 Paris, France, mohamed.berrada@locean-ipsl.upmc.fr), Mark Asch (Université de Picardie Jules Verne, LAMFA (CNRS UMR 6140), 33 Rue Saint Leu, 80039 Amiens, France, mark.asch@u-picardie.fr)
\end{abstract}

In the framework of the recent Maritime Rapid Environmental Assessment sea trial MREA07/BP'07 [Le Gac\&Hermand, 2007] that was conducted in the same area south of the island of Elba as the earlier Yellow Shark trial (YS94), this paper examines the original YS94 acoustic data and the recent MREA07 oceanographic data to demonstrate adjoint-based acoustic monitoring of environmental parameters in Mediterranean shallow waters. First, adjoint-generated environmental gradients are validated for the application in geoacoustic inversion where the bottom acoustic parameters of the YS94 layered seabed are determined from the long-range waterborne propagation of a multi-frequency signal. Then, for the application in ocean acoustic tomography, the temporal variability of the MREA07/BP'07 oceanographic data is analyzed in terms of empirical orthogonal functions and the adjoint-based inversion scheme is used to track the time-varying sound speed profile of the experimental transect.

11:20

4aAO2. Variational assimilation of simulated ocean acoustic tomography data in an ocean model. Elisabeth Remy (MercatorOcean, Parc Technologique du Canal, 8-10 rue Hermès, 31520 Ramonville Saint Agne, France, eremy@mercator-ocean.fr), Fabienne Gaillard (LPO-IFREMER, BP 70, 29280 Plouzane, France, fabienne.gaillard@ifremer.fr), Jacques Verron (Laboratoire des Ecoulements Géophysiques et Industriels (LEGI), BP 53, 38041 Grenoble Cedex 9, France, verron@hmg.inpg.fr)

In the concept of large scale observing system for the ocean, ocean acoustic tomography is an original tool to monitor the ocean interior. Analysis of tomographic travel time using inversion gives an estimate of the temporal evolution of the heat content along the observed sections, an important quantity to monitor the ocean climate evolution. At lower scales than the cell size defined by the observational array, it is not possible to estimate the ocean temperature field without using other sources of information. A possible approach is to combine the tomographic observations with a numerical dynamical ocean model to obtain a complete description consistent with the data on a given time interval. We propose to explore a variational method using the adjoint technic to assimilate those integral data. We studied the case of a basin scale observational array, as the one deployed in the Mediterranean sea for the Thetis 2 experiment. Only travel time anomalies due to the sea water properties are considered. The ability of tomographic data to constrain the ocean model circulation is evaluated using simulated observations with a model solution. This approach called twin experiments, allows to compare the result after assimilation with the "true" solution.

\section{Contributed Papers}

11:40

4aA03. Probabilistic PCA and Ocean Acoustic Tomography Inversion with an Adjoint Method. Mohamed Berrada (Laboratoire d'Océanographie et du Climat - Expérimentation et Approches Numériques, Université Pierre et Marie Curie, Tour 45-55 - 5ème étage - 4, place Jussieu, 75005 Paris, France, mohamed.berrada@locean-ipsl.upmc.fr), Fouad Badran (Laboratoire CEDRIC, Conservatoire National des Arts et Métiers, 292, rue Saint Martin, 75003 Paris, France, badran@cnam.fr), Sylvie Thiria (Laboratoire d'Océanographie et du Climat - Expérimentation et Approches Numériques, Université Pierre et Marie Curie, Tour 45-55 - 5ème étage - 4, place Jussieu, 75005 Paris, France, Sylvie.Thiria@locean-ipsl .upmc.fr)
We present an Ocean Acoustic Tomography (OAT) inversion in a shallow water environment. The idea is to determine the celerity $\mathrm{c}(\mathrm{z}), \mathrm{z}$ is depth, knowing the acoustic pressures caused by a multiple frequencies source and collected by a sparse receiver array. The variational approach minimizes a cost function which measures the adequacy between the measurements and their forward model equivalent. This method introduces also a regularisation term in the form $\left(\mathrm{c}(\mathrm{z})-\mathrm{c}_{\mathrm{b}}\right)^{\mathrm{t}} \mathrm{B}^{-1}\left(\mathrm{c}(\mathrm{z})-\mathrm{c}_{\mathrm{b}}\right)$, which supposes that $\mathrm{c}(\mathrm{z})$ follows an a priori normal law. To circumvent the problem of estimating $\mathrm{B}^{-1}$, we propose to model the celerity vectors by a probabilistic PCA. In contrast to the methods which use PCA as a regularization method and filter the useful information, we take a sufficient number of axes which allow the modelization of useful information and filter only the noise. The probabilistic PCA intro- 